Genentech/Roche, GlaxoSmithKline, Hospira, Janssen, Merck, Novartis, Pfizer, Regeneron Pharmaceuticals, Inc., Sanofi, UCB, Theresa Hunter Shareholder of: Eli Lilly and Company, Employee of: Eli Lilly and Company, David Adams Shareholder of: Eli Lilly and Company, Employee of: Eli Lilly and Company, David Sandoval Shareholder of: Eli Lilly and Company, Employee of: Eli Lilly and Company, Andris Kronbergs Shareholder of: Eli Lilly and Company, Employee of: Eli Lilly and Company, Baojin Zhu Shareholder of: Eli Lilly and Company, Employee of: Eli Lilly and Company, Ann Leung: None declared, Soyi Liu Leage Shareholder of: Eli Lilly and Company, Employee of: Eli Lilly and Company, Victoria Navarro-Compán Consultant of: Abbvie, Lilly, Novartis, Pfizer, UCB, Speakers bureau: AbbVie, MSD, Lilly, Novartis, Pfizer, UCB

DOI: 10.1136/annrheumdis-2020-eular.1969

\section{FRI0287 BIOLOGIC DRUG RESPONSE DOES NOT APPEAR RELATED TO RADIOGRAPHIC STATUS IN AXIAL SPONDYLOARTHRITIS: DATA FROM THE BSRBR-AS REGISTRY}

X. Michelena ${ }^{1}$, S. S. Zhao ${ }^{2}$, S. Dubash ${ }^{1}$, G. T. Jones ${ }^{3}$, L. Dean ${ }^{3}$, H. MarzoOrtega ${ }^{1} .{ }^{1}$ NIHR LBRC, Leeds Teaching Hospitals Trust \& LIRMM, University of Leeds, Leeds, United Kingdom; ${ }^{2}$ Institute of Ageing and Chronic Disease, University of Liverpool, Liverpool, United Kingdom; ${ }^{3}$ Aberdeen Centre for Arthritis and Musculoskeletal Health, University of Aberdeen, Aberdeen, United Kingdom

Background: The concept of axial spondyloarthritis (axSpA) incorporates the full range of inflammatory spinal disease. In the absence of specific immuno-genetic biomarkers, classification criteria differentiate two groups (non-radiographic [nr-axSpA] and radiographic axSpA [r-axSpA]) based on the presence of structural damage of the sacroiliac joints. Controversy remains as to whether nr-axSpA represents a milder form with biologic DMARD (bDMARD) treatment restrictions still in place in many countries.

Table 1. Baseline characteristics of nr-axSpA and r-axSpA patients starting biologics.

\begin{tabular}{|c|c|c|c|c|}
\hline Variables & Level & $\begin{array}{c}n r-a x S p A \\
n=418\end{array}$ & $\begin{array}{c}\text { r-axSpA } \\
n=727\end{array}$ & p-value \\
\hline Age, mean (SD), years & & $39.7(12.4)$ & $46.1(13.4)$ & $<0.001$ \\
\hline Sex, n (\%) & Male & $239(57 \%)$ & $529(73 \%)$ & $<0.001$ \\
\hline $\begin{array}{l}\text { Symptom duration, mean (SD), } \\
\text { years }\end{array}$ & & $11.2(10.9)$ & $16.7(12.9)$ & $<0.001$ \\
\hline $\begin{array}{l}\text { Diagnostic delay, median (IQR), } \\
\text { years }\end{array}$ & & $3.0(1.0,10.0)$ & $3.0(0.0,11.0)$ & 0.83 \\
\hline HLA-B27 (missing=325) & & $227(73 \%)$ & $387(76 \%)$ & 0.40 \\
\hline Inflammatory back pain, n (\%) & & $384(92 \%)$ & $619(92 \%)$ & 0.95 \\
\hline Uveitis, $\mathrm{n}(\%)$ & & $92(22 \%)$ & $205(30 \%)$ & 0.003 \\
\hline Crohn's / Colitis, n (\%) & & $55(13 \%)$ & $113(17 \%)$ & 0.11 \\
\hline Psoriasis, n (\%) & & $79(19 \%)$ & $115(17 \%)$ & 0.43 \\
\hline \multirow[t]{3}{*}{ Smoking status, n (\%) } & Never smoked & $148(43 \%)$ & $218(38 \%)$ & 0.040 \\
\hline & Ex-smoker & $95(28 \%)$ & $207(36 \%)$ & \\
\hline & Current smoker & $100(29 \%)$ & $154(27 \%)$ & \\
\hline NSAID use, $\mathrm{n}(\%)$ & & $311(75 \%)$ & $560(77 \%)$ & 0.43 \\
\hline CRP, median (IQR), mg/dL & & $0.5(0.1,1.3)$ & $0.9(0.3,2.5)$ & $<0.001$ \\
\hline BMI, mean (SD) & & $27.5(5.6)$ & $28.2(5.8)$ & 0.10 \\
\hline BASDAI, median (IQR) & & $6.7(5.4,7.8)$ & $6.5(5.0,7.7)$ & 0.12 \\
\hline BASFI, median (IQR) & & $5.9(4.2,7.8)$ & $6.5(4.4,8.3)$ & 0.043 \\
\hline VAS-G, mean (SD) & & $7.0(2.0)$ & $6.8(2.0)$ & 0.056 \\
\hline ASDAS-CRP, mean (SD) & & $2.8(0.8)$ & $2.8(0.9)$ & 0.32 \\
\hline ASQOL, median (IQR) & & $13.0(9.0,16.0)$ & $13.0(9.0,15.5)$ & 0.29 \\
\hline \multirow[t]{6}{*}{ Biologic (to start), $n(\%)$} & Adalimumab & $238(57 \%)$ & $436(60 \%)$ & 0.20 \\
\hline & Etanercept & $131(31 \%)$ & $220(30 \%)$ & \\
\hline & Certolizumab & $35(8 \%)$ & $47(6 \%)$ & \\
\hline & Golimumab & $5(1 \%)$ & $12(2 \%)$ & \\
\hline & Secukinumab & $7(2 \%)$ & $10(1 \%)$ & \\
\hline & Infliximab & $2(<1 \%)$ & $2(<1 \%)$ & \\
\hline
\end{tabular}

Objectives: To describe the baseline characteristics and bDMARD response at one year in axSpA patients in the British Society for Rheumatology Biologics Register in Ankylosing Spondylitis (BSRBR-AS) according to radiographic status.

Methods: BSRBR-AS is a national prospective cohort including participants who fulfil the ASAS classification criteria for axSpA. In this analysis, cross-sectional baseline data of patients starting bDMARDs including clinical, demographic and patient-reported outcomes (PROs) were compared. Follow-up data at one year was identified if $12 \pm 4$ months from baseline and PROs completed within 2 months of visit date. Ankylosing Spondylitis Disease Activity Scores (ASDAS) for low disease status, clinically important improvement (CII) and major improvement (MI) were used to assess treatment response.
Results: Baseline characteristics were available for 1,145 patients. Those with r-axSpA were more likely to be male, were older, and had longer disease duration (Table 1). Follow-up ASDAS was available in 290 patients. Two thirds of the patients achieved ASDAS low disease state at one year regardless of radiographic status (nr-axSpA: $64.2 \%$ vs r-axSpA: 66.1 , Diff: $-1.9 \%, 95 \% \mathrm{Cl}-13.7$ to 9.8 ). Further, no significant differences were seen between the groups in attaining ASDAS CII (nr-axSpA: $50.7 \%$ vs r-axSpA: $44.7 \%$, Diff: $6.0 \%, 95 \% \mathrm{Cl}-7.8$ to $19.8 \%$ ) or $\mathrm{Ml}$ (nr-axSpA: $20 \%$ vs r-axSpA: $18.7 \%$, Diff: $1.3 \%, 95 \% \mathrm{Cl}-9.7$ to $12.3 \%$ ).

Conclusion: Although there appeared to be some differences in the baseline characteristics when exploring this cohort, according to radiographic status, which are likely related to the natural history of the disease; the level of biologic response was comparable between the groups supporting the concept of axSpA as a single disease entity.

Acknowledgments: This project is supported by a FOREUM fellowship.

Disclosure of Interests: Xabier Michelena: None declared, Sizheng Steven Zhao: None declared, Sayam Dubash: None declared, Gareth T. Jones Grant/ research support from: Pfizer, AbbVie, UCB, Celgene and GSK., Linda Dean: None declared, Helena Marzo-Ortega Grant/research support from: Janssen, Novartis, Consultant of: Abbvie, Celgene, Eli Lilly, Janssen, Novartis, Pfizer, UCB, Speakers bureau: Abbvie, Celgene, Eli Lilly, Janssen, Novartis, Pfizer, Takeda, UCB

DOI: $10.1136 / \pm$ annrheumdis-2020-eular.3147

\section{\begin{tabular}{|l|l|l|l}
\hline FRI0288 TREATMENT PATTERNS AND \\
\hline
\end{tabular} PHARMACOUTILIZATION AMONG PATIENTS AFFECTED BY ANKYLOSING SPONDYLITIS: AN ITALIAN REAL-WORLD STUDY}

V. Perrone ${ }^{1}$, S. Losi ${ }^{2}$, E. Filippi ${ }^{2}$, S. Antonelli ${ }^{2}$, M. Giovannitti ${ }^{3}$, E. Giacomini ${ }^{1}$, D. Sangiorgi ${ }^{1}$, L. Degli Esposti ${ }^{1} .{ }^{1}$ Clicon S.r.l., Health Economics and Outcomes Research, Ravenna, Italy; ${ }^{2}$ Eli Lilly Italy S.p.A., Sesto Fiorentino, Italy; ${ }^{3}$ Eli Lilly Italy S.p.A., Roma, Italy

Background: Ankylosing spondylitis (AS) is a chronic rheumatologic condition requiring lifelong treatments. To date, few real-world studies on AS patients in Italy are reported.

Objectives: Aims of the study were to evaluate treatment patterns and to analyse pharmacoutilization on patients affected by AS in a real-world setting of Italian clinical practice.

Methods: This observational study was based on administrative databases of a pool of Italian settings. A retrospective cross-sectional analysis was performed for years 2015-2017 to evaluate AS-diagnosed patients and, among them, to estimate percentage of treated and untreated ones. Patients were included if having a hospitalization discharge diagnosis at any level of AS (ICD-9-CM: 720.0) or exemption code for AS (054.720.0). Index date (ID) was date in which patients met one of the inclusion criteria. Patients with a prescription for drugs indicated for AS [non-steroidal anti-inflammatory drugs, disease-modifying antirheumatic drugs (DMARDs) - targeted synthetic (tsDMARDs) and biological (bDMARDs)] at ID were defined "treated". Patients without such drug prescriptions at ID were considered "untreated". To analyse treatment patterns of b/tsDMARDs-treated patients a longitudinal cohort study was conducted considering as inclusion periods the year 2014 and a period from 01/07/2016 to 30/06/2017. ID was date of first b/tsDMARDs prescription during inclusion period. Follow-up (F-up) lasted one year after ID. The interruption of treatment was defined as the absence of prescriptions in the last 3 months of F-up.

Results: For cross-sectional-cohort: AS-diagnosed patients were 4,824 in $2015,5,357$ in $2016,5,894$ in 2017 . In all years analysed, about $50 \%$ of patients were male. Mean age \pm SD ranged from $51.5 \pm 13.7$ (2015) to $52.4 \pm 14.0$ (2017). Untreated patients were $33.6 \%(2015), 35.1 \%(2016)$ and $37.9 \%$ (2017), while patients in therapy with b/tsDMARDs were 22.7\% (2015), 22.3\% (2016) and $22.2 \%$ (2017). The remaining percentage of patients were treated with csDMARDs/NSAIDS: 43.7\% (2015), 42.6\% (2016), 39.9\% (2017)). In 2015 and 2016 all b/tsDMARDs-treated patients were in therapy with anti-TFN agents, while the advent of IL-inhibitors was observed starting from 2017 (8.2\% b/tsD MARDs-treated patients with IL-inhibitors). For longitudinal-cohort: in 2014, 310 patients had $a \mathrm{~b} / \mathrm{tsDMARD}$ prescription and during 1-year F-up $11.9 \%$ of them interrupted the treatment after a mean time \pm SD of $83.3 \pm 66.9$ days. Of the 183 patients who had a prescription of b/tsDMARDs at ID during 2016-2017, 22.4\% had a treatment interruption after a mean time \pm SD of $134.4 \pm 86.1$ days during F-up.

Conclusion: This real-world study provided insights on AS treatment patterns. Preliminary results showed that approximately one third of AS patients are untreated and about one in five are treated with b/tsDMARDs. Despite the improvement in treatment duration observed from 2014 to $2016 / 17$, still $22.4 \%$ of $\mathrm{b} / \mathrm{tsDMARDs}$-treated patients interrupted therapy in the most recent cohort. A larger sample size is needed to confirm results. 